\title{
Effect of soil temperature upon the root growth and mycorrhizal formation of white spruce (Picea glauca (Moench) Voss) seedlings grown in controlled environments
}

\author{
L. Husted and D.P. Lavender
}

Department of Forest Sciences, University of British Columbia, Vancouver, Canada

\section{Introduction}

The effects of root zone temperature and mycorrhizal formation on the shoot and root morphology of white spruce seedlings were examined in a controlled environment. A companion study evaluated effects of root zone temperature upon root growth at different stages of seedling growth throughout the year.

\section{Materials and Methods}

3 mo old dormant container-grown white spruce seedlings from a northern British Columbia seed source were inoculated with: 1) Hebeloma crustiliniforme, 2) Thelephora terrestris, 3) forest floor collected from a vigorous northern spruce plantation, 4) peat:vermiculite collected from mycorrhizal (mainly $E$-strain and MRA) container nursery stock, and 5) nothing (control). After inoculation, the seedlings were grown at 3 root zone temperatures: $5-8,15-17$ and $25-29^{\circ} \mathrm{C}$ in a growth cabinet programmed for $19-21^{\circ} \mathrm{C}$ air temperatures, $70-90 \% \mathrm{RH}$ and an $18 \mathrm{~h}$ photoperiod. The root zone temperature and inciculation treatments were factorially arranged to give 15 treatment combinations.

Seedling height and caliper were measured at the initiation of treatment, 5 and 15 wk later. At each sample date, a subsample of seedlings was harvested to estimate needle, stem and root dry weight, length of long roots, short root development and mycorrhizal formation. Mycorrhizal formation was estimated by scanning the surface of the whole root plugs at $12-40 x$ magnification and checking whole mounts at 500-1000x (Danielson and Visser, 1984).

Treatment means for the 15 wk sample were compared by 2-way least squares analysis of covariance using SYSTAT. Initial caliper, the covariate, did not interact significantly with the treatments $(P>0.80)$.

Populations of white spruce seedlings grown in 313 styroblacks under natural conditions commencing in April were placed in controlled environment facilities for 1 mo periods on the following dates: 21/9/87, 21/12/87, 16/5/88, $18 / 7 / 88$. Seedlings were dormant prior to each 
Table I. Effect of soil temperature upon root growth of white spruce.

\begin{tabular}{lrcc}
\hline Date & \multicolumn{3}{l}{$\begin{array}{l}\text { Mean no. of active roots }>1 \mathrm{~cm} \text { in length } \\
\text { soil temp. }{ }^{\circ} \mathrm{C}\end{array}$} \\
\cline { 2 - 4 } & 3 & 10 & 17 \\
\hline Oct. 1987 & $0.8(\mathrm{a})$ & $1.0(\mathrm{a})$ & $5.3(\mathrm{a})$ \\
Jan. 1988 & $24.3(\mathrm{~b})$ & $23.7(\mathrm{~b})$ & $29.7(\mathrm{~b})$ \\
Jun. 1988 & $4.1(\mathrm{a})$ & $32.7(\mathrm{c}, \mathrm{d})$ & $26.7(\mathrm{~b}, \mathrm{c})$ \\
Aug. 1988 & $8.1(\mathrm{a})$ & $34.6(\mathrm{~d})$ & $44.8(\mathrm{e})$ \\
\hline
\end{tabular}

Numbers followed by same letter are not significantly different.

trials, but doubtless had different physiologies. Seedlings were maintained out-of-doors before the first 2 trials; were stored at $2^{\circ} \mathrm{C}$ in darkness for the period Dec 87-May 88, a common B.C. practice; and had recently completed the 2 nd $y r$ growth flush in July 88 . The growth chambers were programmed for $14 \mathrm{~h}$ daily photoperiods with a constant air temperature of $20^{\circ} \mathrm{C}$ and soil temperatures of 3,10 and $17^{\circ} \mathrm{C}$. Seedling caliper and shoot length were measured prior to and after the treatment period. The number of actively growing roots greater than $1 \mathrm{~cm}$ in length was recorded when the seedlings were harvested. These data were analyzed by Duncan's multiple range test for significant differences at $P=0.05$ (Table I).

\section{Results}

Mycorrhizae formed following all the inoculation treatments at the $15-17^{\circ} \mathrm{C}$ root zone temperature. However, at the $5-8^{\circ} \mathrm{C}$ root zone temperature, mycorrhizae were formed only by $T$. terrestris and forest floor symbionts (Amphinema-like species and several unidentified ascomycetes); at the $25-29^{\circ} \mathrm{C}$ root zone temperature, mycorrhizae were formed only by $T$. terrestris and E-strain. Accordingly, analyses of interactions between inoculation and temperature treatments on seedling morphology were conducted using 3 classes of mycorrhizal formation: 1) no mycorrhizae, 2) mycorrhizae formed by T. terrestris and 3) mycorrhizae formed by other fungal species.

There was no evidence of interactions between temperature and mycorrhizal class on root or shoot morphology $(P>0.50)$. With two exceptions, root zone temperature accounted for significantly more of the variation in root data than did mycorrhizal class. The two exceptions were the number of short roots: 1) per unit root dry weight and 2) per unit root length. Root dry weight, length and short root numbers increased $(P<0.01)$ with root zone temperature up to $15-17^{\circ} \mathrm{C}$. Raising the temperature to $25-29^{\circ} \mathrm{C}$ did not affect these root parameters $(P>0.60)$. Mycorrhizal formation by other fungal species increased the ratio of short roots produced per unit root dry weight or length $(P=0.02)$ compared to no or $T$. terrestris mycorrhizae.

Buds were dormant until 1 wk prior to final harvest when most flushed, with the flushing rate independent of root zone temperature or mycorrhizal formation 


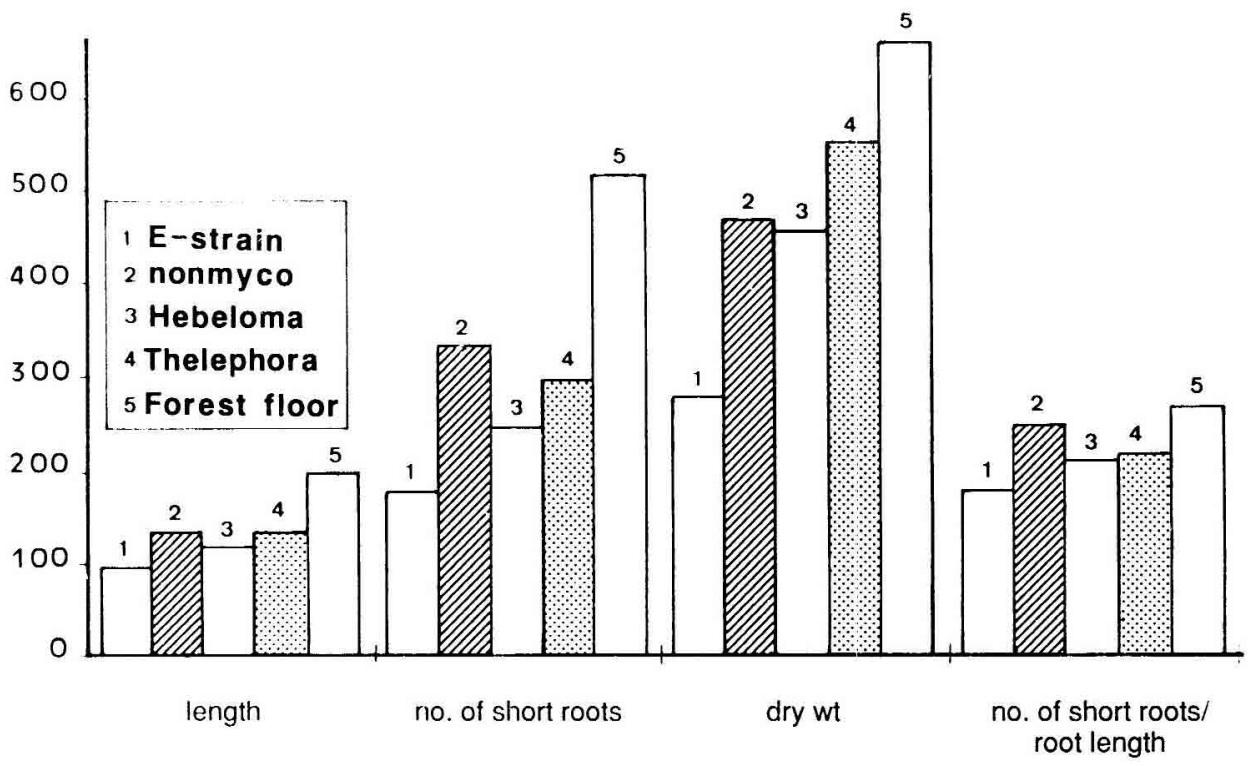

Fig. 1. Effect of mycorrhizae at the $15-17^{\circ} \mathrm{C}$ root zone temperature on white spruce seedling lateral root length $(\mathrm{cm})$. number of short roots. root dry weight $(\mathrm{mg})$ and number of short roots per unit root length (x100).

$(P>0.05)$. Needle dry weight and caliper increased during the 15 wk experiment with final needle dry weight inversely related to root zone temperature. Mycorrhizal formation accounted for more of the variability in final caliper than did temperature. The data suggest that caliper growth was greatest when seedlings were colonized by other species $(P=$ 0.09).

The 5 inoculation treatments were compared for the $15-17^{\circ} \mathrm{C}$ root zone temperature. Shoot parameters were not influenced by inoculation treatments. However, forest floor inoculum increased short root development $(P=0.02)$, root length $(P=0.01)$ and weight $(P=0.14)$ compared to the other treatments (Fig. 1). The comparison of mycorrhizal to nonmycorrhizal seedlings was not significant for any root parameter $(P>0.25)$.

\section{Discussion and Conclusion}

For most shoot and root parameters, temperature accounted for more variability in the data than did mycorrhizal formation. However, for several parameters (number of short roots per unit root dry weight or length, calliper growth), mycorrhizal formation was a more important source of variation than temperature. Seedlings with $T$. terrestris mycorrhizae or no mycorrhizae were not significantly different in these parameters; seedlings with mycorrhizae formed by 'other' species, particularly from the forest floor inoculum, had higher values for these parameters.

Cold soils are believed to limit white spruce seedling growth in British Columbia. Present data (Table I) demonstrate that current cold storage procedures exacerbate this situation for a large pro- 
portion of planted spruce seedlings. Earlier data (Lavender, 1988) suggested that a daily photoperiod during cold storage could reduce the impact of this practice.

\section{Acknowledgments}

Support for the above research from F.R.D.A grants numbers $5-56188$ and $5-56191$ to D.P. Lavender.

\section{References}

Danielson R.M. \& Visser S. (1984) Mycorrhizal status of container-grown conifers in the Pine Ridge Provincial Nursery. Annual report submitted to Research Management Division of Alberta Environment, RRTAC. pp. 32-45

Lavender D.P. (1988) Characterization and manipulation of the physiological quality of planting stock. Proceedings of the Tenth North American Forest Biology Workshop. (Lester D.L. \& Worrall J.G., eds.), University of British Columbia, Vancouver, B.C. in press 